\title{
Highlights from the Current Issue -
}

\section{Audiovisual Summary}

Thomas Gerber, MD, Associate Editor

Dr Thomas Gerber, Associate Editor for Mayo Clinic Proceedings, discusses the articles featured on the cover and website home page of the October 2012 issue. These include:

"Ideal Cardiovascular Health and Mortality:

The Aerobics Center Longitudinal Study,"

by Dr Enrique G. Artero and colleagues;

"The High Cost of Cancer Drugs and What We Can Do About It," by Drs Mustaqueem Siddiqui and S. Vincent Rajkumar;

"Ten Common Questions (and Their Answers) About Off-label Drug Use," by Dr Christopher M. Wittich and colleagues;

"Asthma and Proinflammatory Conditions:

A Population-Based Retrospective Matched Cohort Study,"

by Dr Hyun D. Yun and colleagues;

"Melanoma in Immunosuppressed Patients,"

by Drs Agnieszka W. Kubica and Jerry D. Brewer;

"Human Herpesviruses 6, 7, and 8 From a Dermatologic Perspective," by Dr Michael M. Wolz and colleagues; and

"Clinical Pearls in Breast Disease,"

by Dr Sandhya Pruthi and colleagues. 